\title{
FRS Election as a Recognition for Scientists of Colonial India
}

\author{
Arnab Rai Choudhuri* \\ (Received 4 April 2018; revised 4 July 2018)
}

\begin{abstract}
In the early decades of the twentieth century, an Indian scientist was likely to be nominated for the Fellowship of the Royal Society only if his work was sufficiently known among his British peers. Several Indians were nominated and a few were elected FRS. Even those who were not elected appear to be key figures in our understanding of Indian science of that era.
\end{abstract}

Key words: C V Raman, Fellowship election process, Indian Fellows, M N Saha, Royal Society, Unsuccessful Indian nominations for FRS.

\section{INTRODUCTION}

When C V Raman and K S Krishnan were sure that they were on the verge of a major discovery, Krishnan wrote in his diary on 9 February 1928: 'he [Raman] remarked that nothing was beyond my reach referring to the Fellowship of the Roy[al] Soc[iety] and that I might probably get the Fellowship before I got my Doctorate' (Mallik, 2000). This quotation from Krishnan's diary makes it clear that the FRS or the Fellowship of the Royal Society of London was undoubtedly the most coveted honour for the pioneers of modern science in colonial India in the early decades of the twentieth century.

If you ask a scientist what motivates him/ her to carry on scientific research, in most cases you will get the answer that the joy of doing scientific research is the only motivation and the scientist does not care much about honours or awards. You may form the opinion that scientists are ideal examples of the kind of persons who have been called 'sthitaprajū $\bar{a}$ ' in the Bhagavad git $\bar{a}$. However, a deeper probe will reveal that scientists are human beings and do indeed crave for honours and recognition like other human beings. In the 1930s, science academies started being established in India. Here I shall not get into the complicated history of why India has three science academies. All these academies, including INSA where we are having our conference, elect Fellows exactly like the Royal Society. As these Indian academies gained in stature, being elected a Fellow of one of these academies became an important recognition for an Indian scientist - although the Fellowship of none of these academies still compares in prestige with the Fellowship of the Royal Society. Before the establishment of these Indian academies, the Fellowship of the Royal Society was the main recognition an Indian scientist aspired for. While the Nobel Prize might have been the ultimate goal, it was realized that this Prize was for only truly exceptional work. On the other hand, a handful of scientists from colonial India were elected Fellows of the Royal Society.

\section{The Royal Society and its Fellowship Election Process}

The Royal Society of London was established in 1660 - in an era of political turbulence in

\footnotetext{
*Department of Physics, Indian Institute of Science, Bangalore-560012, Email: arnab@iisc.ac.in
} 


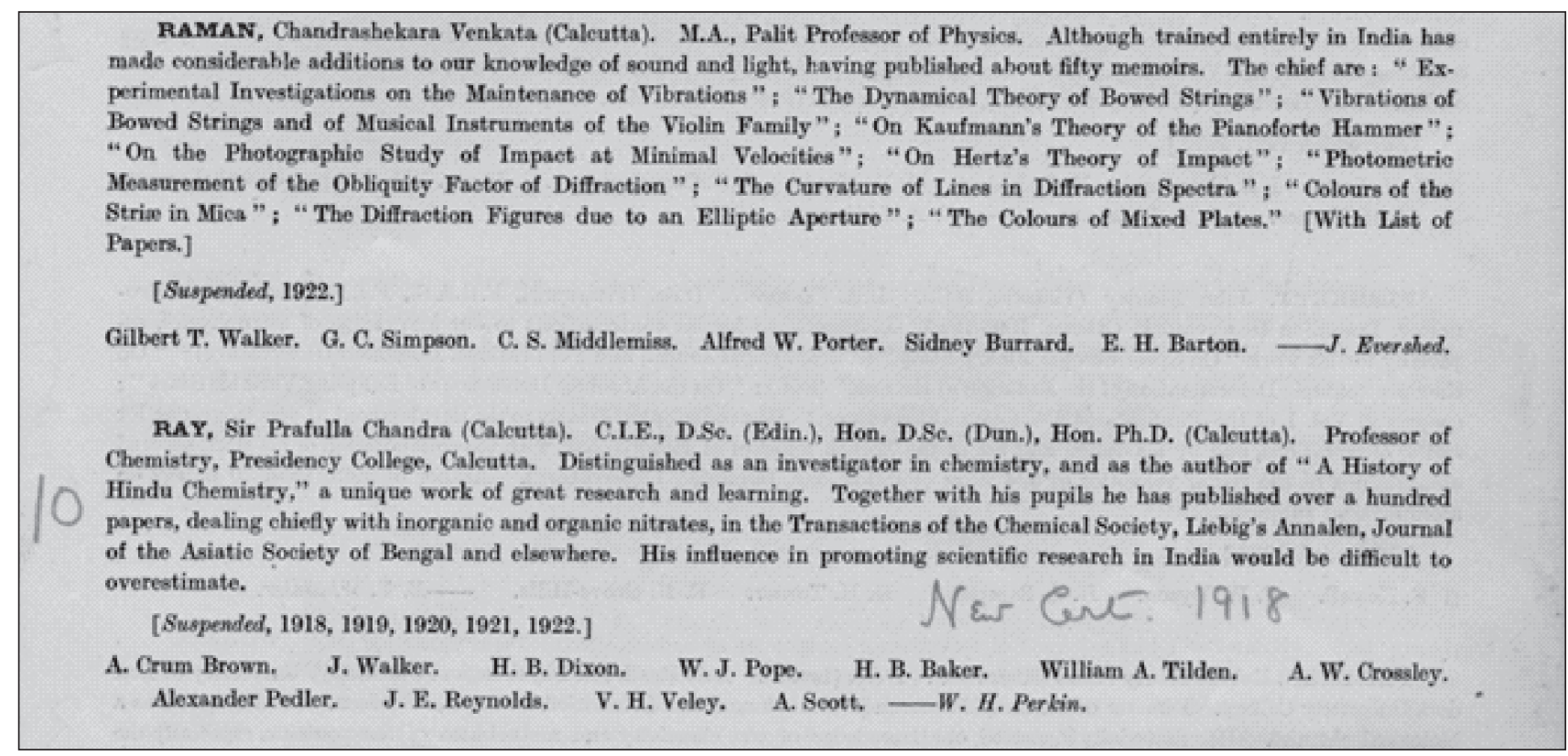

Fig. 1. The nomination statements of C V Raman and P C Ray (with the list of nominators) as they appeared alphabetically in the nomination list of 1922 (Credit: Royal Society Archives).

England barely a decade after the execution of King Charles I (in 1649). According to a contemporary writer (Sprat, 1667, p. 53):

Their first purpose was no more, then onely the satisfaction of breathing a freer air, and of conversing in quiet one with another, without being ingag' $d$ in the passions, and the madness of that dismal Age.

Until the Royal Society adopted a set of new Statutes in 1847 , the Society was not too unlike a gentlemen's club. Robert Clive and Warren Hastings, two builders of the British Empire in India, were FRS! The only ethnic Indian to be elected FRS in that era before 1847 was Ardaseer Cursetjee, elected in 1841. Although not a scientist in the usual sense of the term, he was nevertheless a remarkable man - a shipbuilder of Bombay who had also 'introduced Lighting by Gas into Bombay' (Kochhar, 1993).

After the adoption of the new Statutes in 1847 (available at the Royal Society Archives), eminence in some branch of science became the primary criterion for FRS election. Only a person who was 'one of Her Majesty's subjects' could be considered for election as Ordinary Fellow. Such a person had to be nominated by at least six Fellows of the Society in writing. This nomination would remain valid for five years. During the years when the nomination remained valid, the statement in the nomination certificate (along with the list of nominators) would be included in a list prepared for circulation among the Fellows. Fig. 1 shows a portion of a page from the list of 1922 in which the nomination statements of C V Raman and P C Ray appear one after the other in alphabetical order. The Royal Society would elect only 15 new Fellows per year in the early decades of the twentieth century till 1931, though this number was gradually increased in later years (Andrade, 1960, pp. 12-13). The selection would be primarily made by the Council of the Royal Society, although there would a formal voting within the Fellows. It is clear that many persons who were nominated for FRS would not get elected. 


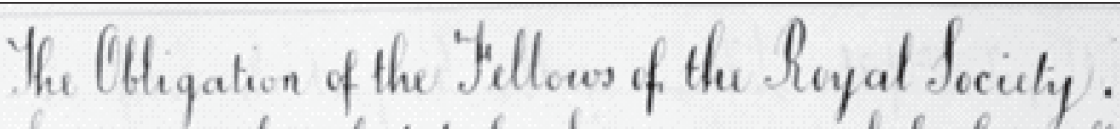

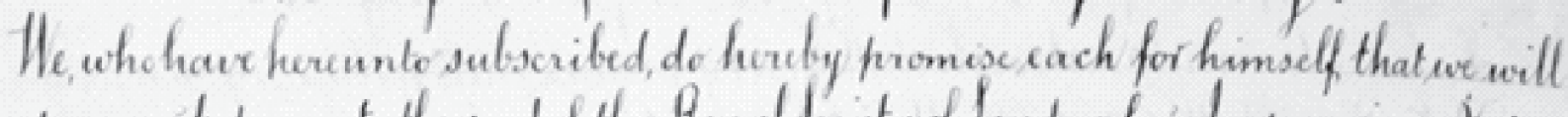

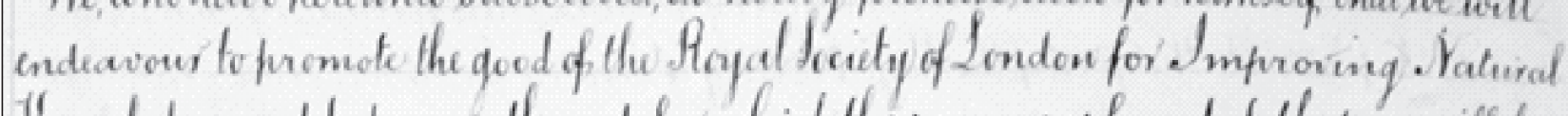

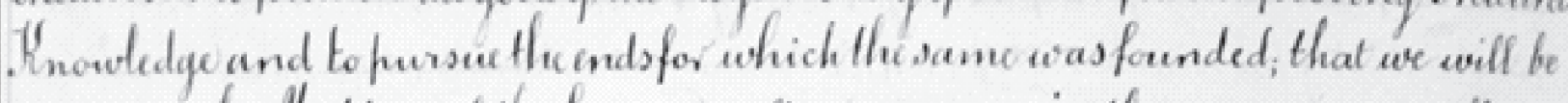

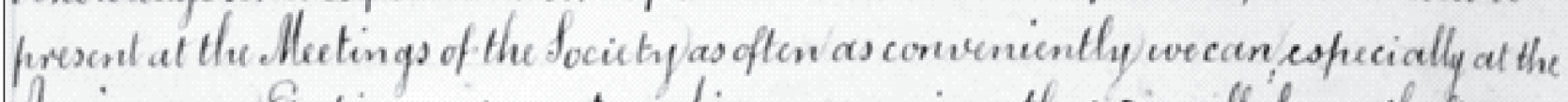

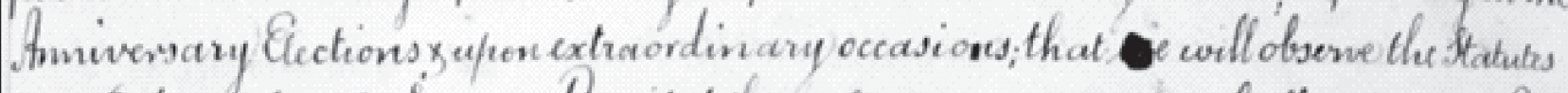

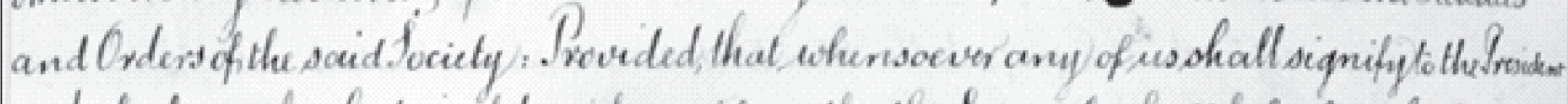

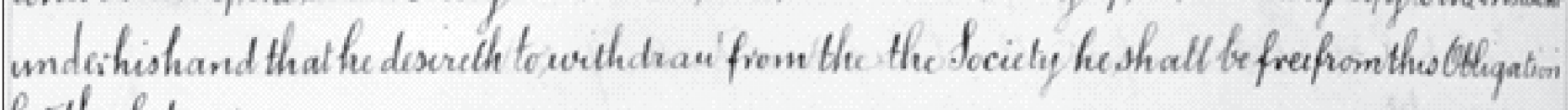
forthe future.

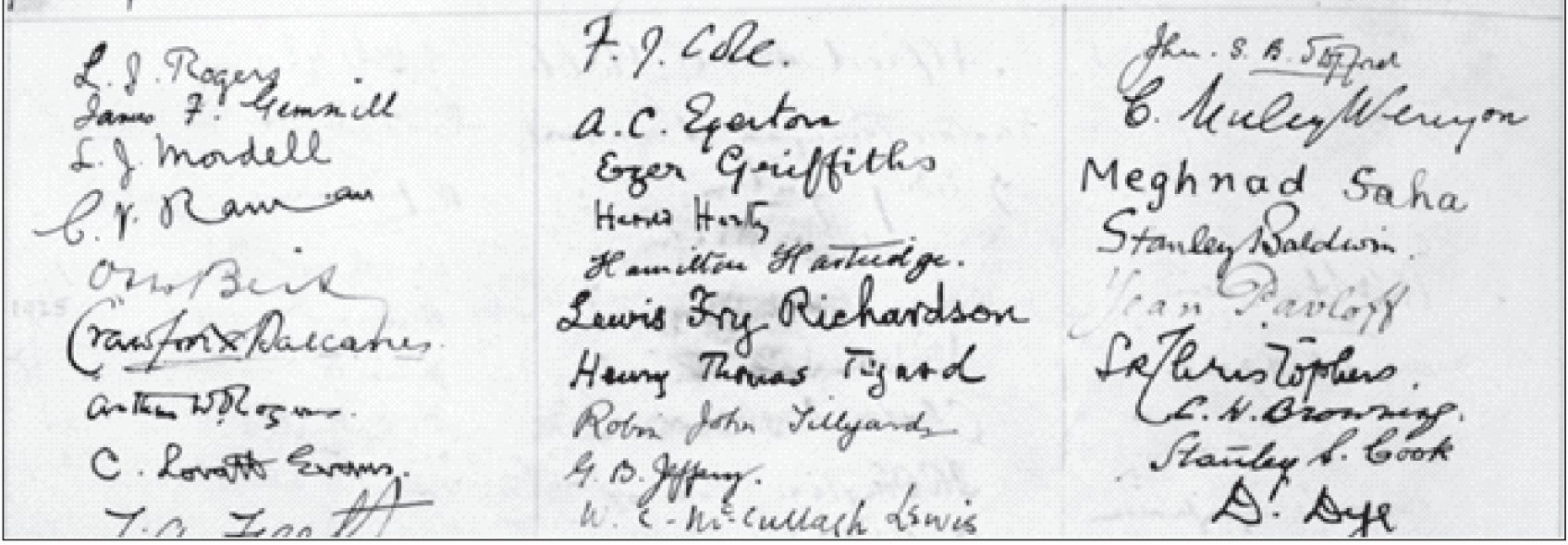

Fig. 2. The page from the Charter Book of the Royal Society in which the signatures of C V Raman (fourth in the left column) and Meghnad Saha (third in the right column) appear (Credit: Royal Society Archives).

The final ceremony of the Fellowship election process would be the signing of the Charter Book of the Royal Society, which bore signatures of such luminaries as Newton, Hooke, Boyle and Wren in its earlier pages. Fig. 2 shows a page of the Charter Book in which the signatures of C V Raman (elected in 1924) and M N Saha (elected in 1927) appear. Obviously, an Indian who was elected FRS could sign the Charter Book only when he visited London. The visit of British scientist Archibald Hill to India in 1943 was significant for various reasons (Kumar, 2006, pp. 253-257; Anderson, 2010, pp. 109-114). At that time, it was noted that as many as four out of six living Indian Fellows had not signed the Charter
Book and Hill took a sheet of parchment with him to obtain the signatures of these Indian Fellows an unusual step taken by the Royal Society 'without precedent in its long history' (Letter from President of Royal Society to President of Indian Science Congress dated $29^{\text {th }}$ October 1943, Royal Society Archives).

\section{Indian Nominations fOR FRS}

Throughout the colonial era, many British scientists working in India were elected FRS. According to Home (2003) who had done an extensive study of the nominations from the colonies of the British Empire: 
Many were clearly admitted on the basis of the senior positions that they held in government scientific agencies rather than the originality or the intrinsic merit of their research.

Here we are interested only in the FRS nominations of ethnic Indian scientists for whom the bar was much higher, as they would not typically belong to any 'old boys' network'. In an era when there were very few Indian Fellows, an Indian scientist had to be nominated primarily by his British peers. We can easily imagine that in the final selection process, through debates within the Council of the Royal Society, an outsider would clearly be in a disadvantageous position. It is significant to note that the nomination statement of Raman (shown in Fig. 1) begins with the phrase 'Although trained entirely in India has made remarkable additions to our knowledge of sound and light', as if such an achievement was not expected from somebody who was 'trained entirely in India'!

Since P C Ray and J C Bose were the first Indian scientists to achieve high international reputation, it is no wonder that they were the first Indians of the modern era to be nominated for FRS (in 1913 and 1915 respectively). However, Srinivasa Ramanujan became the first Indian of this era to be elected FRS in 1918 - G H Hardy playing a key role in the election process by stressing Ramanujan's deteriorating health condition (Kanigel, 1991, pp, 291-295). Table 1 lists all the Indians who had been nominated for FRS from that time till the Indian independence. It is curious to note that $\mathrm{S} \mathrm{N}$ Bose was never nominated for FRS during the colonial era. Much later in 1958, after Dirac found out during his trip of India that S N Bose was not an FRS, Dirac took the initiative of nominating him and he was elected in the first year of his nomination. J C Ghosh is the other important Indian scientist of that era who seems never to have been nominated for FRS, although he received the other important honour of the British Empire - knighthood - for his scientific contributions.
Table 1. Indian scientists nominated for FRS during the colonial era. For those who were elected, the year of election is indicated in bold

\begin{tabular}{|c|c|}
\hline Names & Nomination years \\
\hline Prafulla Chandra Ray & $\begin{array}{c}1913-17,1918-22 \\
1934-38\end{array}$ \\
\hline Jagadis Chandra Bose & 1915-1919, 1920 \\
\hline Srinivasa Ramanujan & 1918 \\
\hline Devendra Nath Mallik & $1919-23$ \\
\hline Chandrasekhar Venkata Raman & 1922-1924 \\
\hline Meghnad Saha & 1925-1927 \\
\hline Raghavendra Row & 1926-30 \\
\hline Nil Ratan Dhar & $1927-31,1932-36$ \\
\hline Birbal Sahni & 1932-1936 \\
\hline Sudhansu Kumar Banerji & 1933-37 \\
\hline L.K. Ananthakrishna Iyer & $1935-38$ \\
\hline Kariamanikkam Srivivasa Krishnan & 1936-1940 \\
\hline Shanti Swarup Bhatnagar & $\begin{array}{c}\text { 1937-41, } \\
1942-\mathbf{1 9 4 3}\end{array}$ \\
\hline Homi Jehangir Bhabha & 1941 \\
\hline Upendra Nath Brahmachari & $1942-46$ \\
\hline Subramanian Chandrasekhar & 1942-1944 \\
\hline Prasanta Chandra Mahalanobis & 1942-1945 \\
\hline Karm Narayan Bahl & $1943-47$ \\
\hline Daulat Singh Kothari & $1944-48$ \\
\hline Suri Bhagavantham & $1945-49$ \\
\hline Rappal Sangameswara Krishnan & $1945-49$ \\
\hline Sisir Kumar Mitra & $\begin{array}{c}1945-49 \\
\text { (elected later } \\
\text { in 1958) }\end{array}$ \\
\hline Jnanendra Nath Mukherjee & $1945-49$ \\
\hline Rames Chandra Ray & $1945-49$ \\
\hline
\end{tabular}

The Archives of the Royal Society have preserved many important documents connected with the Fellowship election process, some of which are available online. For example, the nomination certificates of the all the Fellows are available online. Additionally, in a few cases, records of the deliberations of the Council regarding the election of a candidate have also been preserved, although one has to consult such documents at the Archives of the Royal Society (they would be listed in the online catalogue, but the full documents would not be available online). For example, when M N Saha was nominated, an 
enquiry was made whether his connections with Indian revolutionaries in his youth could be an embarrassment for the Royal Society. The letters exchanged on this subject have been preserved and studied (DeVorkin, 1993, pp. 182-184). It may be noted that $\mathrm{J} C$ Bose was elected FRS at a time when several influential British plant physiologists were highly critical of his research (Dasgupta, 1999, Chapter 6). One would be curious to know what discussions took place within the Council during his election. However, no records are available on this.

\section{UnSUCCESSFUL FRS NOMINATIONS}

No information about unsuccessful FRS candidates before about 1940 is available online. A table like Table I had to be compiled from the yearly nomination lists available only at the Royal Society Archives. Apart from the nomination statements (with the names of nominators) given in the nomination lists, even the Archives would not normally have any other materials on the unsuccessful candidates before 1940. However, in a few cases of unsuccessful candidates after 1940, some materials are available regarding their nominations. For example, in the case of $\mathrm{U} \mathrm{N}$ Brahmachari whose nomination was unsuccessful, enquiries that were made about his scientific reputation have been preserved (Singh, 2014).

Since only an Indian scientist with high reputation among his British peers had a chance of being nominated for FRS in the early decades of the twentieth century, all the unsuccessful FRS nominees of that era were remarkable persons who should be of great interest to any historian of science studying this era of Indian science. Prafulla Chandra Ray and Nil Ratan Dhar were, of course, pioneering Indian chemists who had high international reputations, and it is somewhat of a mystery why they were not elected (Choudhuri \& Singh, 2018). When Ray's nomination was being considered by the Royal Society, his favourite student Dhar was carrying on research in London and Paris, and lobbied with several leading British chemists for Ray's election. Dhar gave an account of his lobbying in a series of fascinating letters to Ray, which provide a rare glimpse of what election to the Royal Society meant for an Indian scientist of this era (Choudhuri \& Singh, 2018). It may be mentioned that, while several Indian physicists were elected FRS in the early decades of the twentieth century, no Indian chemist was elected before the election of S S Bhatnagar in 1943.

The other four unsuccessful nominees before World War II were: (i) Devendra Nath Mallik - a popular professor of mathematics in Presidency college who carried on research in mathematical physics and was nominated by such luminaries as Larmor, Lodge and Rutherford; (ii) Raghavendra Row - the first Indian to obtain DSc from University of London and a pioneer in medical research; (iii) Sudhansu Kumar Banerjee - a student of Raman who changed his research expertise to become India's first important geophysicist and was Raman's first student whom he nominated for FRS (a few years before he nominated Krishnan) and (iv) L K Ananthakrishna Iyer - who became India's first important anthropologist without receiving any proper training in the subject and carried on pioneering studies on the tribes of Cochin and Mysore states. These extremely important scientists are almost completely forgotten now and their FRS nomination statements (available only in the annual nomination lists of the Royal Society) may be the most comprehensive brief summaries of their scientific accomplishments that we have today. As I started collecting more information about them, I became fascinated about them and I have no doubt that they would be key figures for a historian of science who may want to find out what was happening in Indian science at large in that era beyond the circles of a few famous scientists. I am right now in the process of preparing a paper on the unsuccessful FRS nominees from colonial India (Choudhuri, 2018). 


\section{Conclusion}

The aspiration of the scientists of colonial India for FRS election provides an interesting case study of the metropolis-periphery relationship in the process of transplantation of science. Western science was introduced to colonial India by her British rulers and scientists belonging to the periphery that was India craved for recognition from the metropolis, although it was clearly realized that outsiders had a higher bar to be accepted into the Royal Society compared to those who belonged to the British scientific establishment. Since only Indian scientists with sufficiently high reputation among British peers had a chance of being nominated for FRS in the early decades of the twentieth century, the Indians nominated for FRS during this era constitute a remarkable group of men representative of the nascent Indian scientific community.

\section{ACKNOWLEDGeMentS}

I am grateful to the staff of the Royal Society Archives for their help and co-operation during my visit of these marvelous Archives on 24 and 25 July 2017. I thank Deepak Kumar and Rajinder Singh for valuable discussions. My research is supported by a $\mathrm{J} C$ Bose Fellowship awarded by DST.

\section{BiBLIOGRAPHY}

Anderson, Robert S. Nucleus and Nation, University of Chicago Press, Chicago, 2010.

Andrade, E N da C. A Brief History of the Royal Society, Royal Society, London, 1960.
Choudhuri, Arnab Rai. Unsuccessful FRS nominations from colonial India, Indian Journal of History of Science (to be submitted).

Choudhuri, Arnab Rai and Singh, Rajinder. The FRS nomination of Sir Prafulla C Ray and the correspondence of N R Dhar, Notes and Records: the Royal Society Journal of the History of Science 72 (2018), 57-73.

Dasgupta, Subrata. Jagadis Chandra Bose and the Indian Response to Western Science, Permanent Black, Ranikhet, 1999.

DeVorkin, D H. Saha's influence in the West: A preliminary account, in S B Karmohapatra (ed), Meghnad Saha Birth Centenary Commemoration Volume, Saha Institute of Nuclear Physics, Calcutta, 1993, pp. 154202.

Home, R W. The Royal Society and the Empire: The colonial and Commonwealth Fellowship Part 2. After 1847, Notes and Records of the Royal Society of London 57 (2003):47-84.

Kanigel, Robert. The Man who knew Infinity, Washington Square Press, New York, 1991.

Kochhar, R K. Ardaseer Cursetjee (1808-1877), the first Indian Fellow of the Royal Society of London, Notes and Records of the Royal Society of London 47 (1993):33-47.

Kumar, Deepak. Science and the Raj (second edition), Oxford University Press, New Delhi, 2006.

Mallik, D C V. The Raman Effect and Krishnan's Diary, Notes and Records of the Royal Society of London 54 (2000):67-83.

Singh, Rajinder. Sir Upendranath Brahmachari and the Fellowship of the Royal Society of London, Science and Culture, 80 (2014): 29-37.

Sprat, Thomas. The History of the Royal-Society of London, London, 1667. 